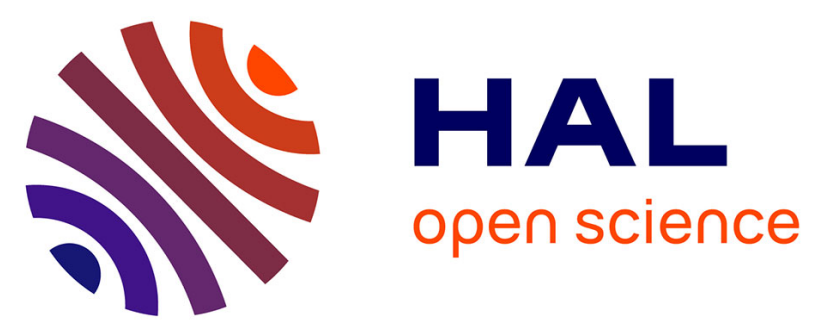

\title{
Natural weathering of hemp fibers reinforced polypropylene biocomposites: Relationships between visual and surface aspects, mechanical properties and microstructure based on statistical approach
}

Célia Badji, J. Beigbeder, Hélène Garay, Anne Bergeret, Jean-Charles Benezet, Valérie Desauziers

\section{To cite this version:}

Célia Badji, J. Beigbeder, Hélène Garay, Anne Bergeret, Jean-Charles Benezet, et al.. Natural weathering of hemp fibers reinforced polypropylene biocomposites: Relationships between visual and surface aspects, mechanical properties and microstructure based on statistical approach. Composites Science and Technology, 2018, 167, pp.440-447. 10.1016/j.compscitech.2018.08.036 . hal-02479341

\author{
HAL Id: hal-02479341 \\ https://hal.science/hal-02479341
}

Submitted on 20 Feb 2020

HAL is a multi-disciplinary open access archive for the deposit and dissemination of scientific research documents, whether they are published or not. The documents may come from teaching and research institutions in France or abroad, or from public or private research centers.
L'archive ouverte pluridisciplinaire HAL, est destinée au dépôt et à la diffusion de documents scientifiques de niveau recherche, publiés ou non, émanant des établissements d'enseignement et de recherche français ou étrangers, des laboratoires publics ou privés. 


\title{
Natural weathering of hemp fibers reinforced polypropylene biocomposites: Relationships between visual and surface aspects, mechanical properties and microstructure based on statistical approach
}

\author{
Célia Badji, Joana Beigbeder, Hélène Garay*, Anne Bergeret, Jean-Charles Bénézet, \\ Valérie Desauziers
}

C2MA, IMT Mines Alès, 6 avenue de Clavières, 30319, Cedex, France

\begin{abstract}
A B S T R A C T
Two natural weathering of neat polypropylene (PP) and hemp fibers reinforced PP biocomposites were investigated. The objective was to emphasize the relationships between the properties of materials according to the fiber loading and the weathering time in order to bring new insights of degradation mechanisms understanding. For this purpose, a Principal Component Analysis (PCA) method was applied to the dataset. The treatment carried out by isolating materials loaded by the three different hemp fiber rates particularly outstand the link between mechanical properties and products issued from oxidation. The close correlation between whitening parameter and $\mathrm{C}=\mathrm{C}$ bond level also confirmed the lignin degradation way. Finally, depending on the weathering duration, the properties characterized either fiber loading or weathering state (unweathered or weathered) whereas mechanical performance differentiated the three different non-weathered samples whatever the exposure time.
\end{abstract}

Keywords:

Ageing

Statistical method (C)

Hemp fibers (A)

Relationships

\section{Introduction}

The use of natural fibers for thermoplastics reinforcement results from the will of developing materials based on renewable resources as alternatives for fossil ones. Biocomposites combine advantages such as stiffness and recyclability. However, the high sensitivity of vegetal fibers impedes their extensive application. Indeed, UV rays sensitivity, thermal instability and moisture absorption are responsible to the broad variability of their properties [1,2]. Since several decades, several works investigated the influence of ageing on their mechanical and visual aspect properties. Biocomposites strongly lost strength and stiffness [3-7] and the presence of natural fibers were evidenced to give rise to materials surface defects, gloss being compromised by these surface aspect changes $[3,8,9]$. The natural reinforcing part also instigated the biocomposites discoloration by photo-induced oxidation $[3,9,10]$. Some solutions can be brought to avert these variations, for example by adding chemical stabilizers [11]. However, in order to effectively intervene, the degradation mechanisms must be handled. The elucidation of relationships between the properties governing the variations in biocomposites during weathering is besides required to assess durability.

Well-known relationships exist between structure and properties of thermoplastic polymers [12-15]. Relationships between properties of thermoplastics determined all along their weathering have been investigated. A correlation between modification of crystalline fraction and detection of micro-cracks after polypropylene (PP) accelerated ageing was deduced from microscopy and calorimetry analyses [8]. But this observation cannot be verified by regression and remains crude correlation. On the contrary, the interdependence between parameters was sometimes quantified. For instance, a linear relationship between the crystallinity ratio $\chi_{c}$ and the inverse of the square root of weightaverage molecular weight $\mathrm{M}_{\mathrm{w}}$ of high density polyethylene (HDPE) was assumed for quenched HDPE [16]. However, this linear relationship could not describe crystallisation behaviour of other HDPE samples. Also, the absorption bands corresponding to crystalline and amorphous phases and allowing to measure the crystallinity of HDPE were proved to be well correlated with the melting enthalpy over a natural weathering during Canadian winter [17]. Indeed, because of the formation of bulky groups, the melting enthalpy (i.e. crystallinity) progressively decreased during the ageing process as well as the crystalline content determined from 1464 and $1474 \mathrm{~cm}^{-1}$ infrared bands. So a close link between chemical composition and microstructure evolution was verified and demonstrated that ageing was caused by chemical structure modification leading to configuration changes such as chain breaking,

\footnotetext{
* Corresponding author.

E-mail address: helene.garay@mines-ales.fr (H. Garay).
} 
chain branching and oxidation. Torikai et al. demonstrated that for PE samples having the same structure (crosslinked or uncrosslinked) but differing according to the type of antioxidant, the amount of oxidation products versus strength at break after photodegradation lie on a same curve [18]. The carbonyl content (oxidation degree) increased and the strength at break decreased in a same way regardless of the type of antioxidant. Hence, a simple method such as infrared spectroscopy could allow predicting the photostability of polymeric materials. In contrast to this approach, other authors reported that no simple relationship exists between the changes in chemical structure and mechanical properties $[13,19]$.

Fewer studies focused on relationships between properties of biocomposites determined all along their weathering. Fabiyi evidenced strong correlations between lightness and chemical composition (carboxylic acid and ester concentrations) evolutions over an exterior weathering of wood plastic composites (WPC) with good correlation coefficients [20]. Indeed, lightness proportionally increased with the concentration of molecules containing carbonyl groups. Thus, in these degradation conditions, lightness could be a useful direct predictive indicator of chemical structure changes. However, until today, the relationships between properties of biocomposites were assessed two by two and not all simultaneously. Principal Component Analysis (PCA) is a useful statistical technique for finding relationships between parameters in high-dimensional dataset by including several parameters at a same time. In a previous paper, the correlations between properties of PP and WPC were assessed after natural and artificial weathering thanks to this analysis [3].

Nevertheless, the progressive evolution of relationships between chemical, physical and mechanical properties of materials over their exposition under real conditions representing their end use has not been studied. This work aims to carry out PCA on two types of weathering simulating car interior and decking of PP and hemp fibers/PP biocomposites towards different criteria consideration (fiber rate and time of exposure) to determine the influence of the different parameters. The objective is to highlight the relationships existing between all measured properties simultaneously for a better understanding of their degradation mechanisms.

\section{Materials and methods}

\subsection{Raw materials}

Polypropylene (PP, grade H733-07) with a melt flow rate of $7.5 \mathrm{~g} /$ $10 \mathrm{~min}\left(230^{\circ} \mathrm{C}, 2.16 \mathrm{~kg}\right)$ obtained from Braskem (Brazil) in the form of pellets was used as homopolymer matrix. Hemp fibers provided by AgroChanvre (France) were sifted to obtain 2-6-mm length range. Anhydride grafted polypropylene (MA-g-PP, Orevac CA100) with a $1 \mathrm{wt}$ $\%$ grafting rate purchased from Arkema (France), was added at $3.1 \mathrm{wt} \%$ of PP as coupling agent. The hemp fibers were added at $10 \mathrm{wt} \%$ (PP10) and $30 \mathrm{wt} \%$ (PP30) in the (PP + MA-g-PP) part.

\subsection{Process conditions}

Once oven-dried for $15 \mathrm{~h}$ at $60^{\circ} \mathrm{C}$, PP and MA-g-PP granules were mixed with hemp fibers in a BC21 Clextral co-rotating twin-screw extruder ( $\mathrm{L} / \mathrm{D}=36$ with the diameter $\mathrm{D}=25 \mathrm{~mm}$ and $\mathrm{L}=900 \mathrm{~mm}$ ) (Clextral, France) with the temperature ranging from 190 to $175^{\circ} \mathrm{C}$ from feed to die and a screw speed of $220 \mathrm{rpm}$. Once dried for 3 days at $60^{\circ} \mathrm{C}$, extruded pellets were injection molded in a Krauss Maffei KM50$\mathrm{T} 180 \mathrm{CX}$ at $210^{\circ} \mathrm{C}$ (Krauss Maffei, Germany) with an injection speed of $30 \mathrm{~cm}^{3} \mathrm{~s}^{-1}$ and a mold kept at $40^{\circ} \mathrm{C}$. ISO 1 dog-bone specimens and square specimens of $100 \times 100 \times 2 \mathrm{~mm}^{3}$ and were obtained for both mechanical performance and visual appearance characterizations respectively.

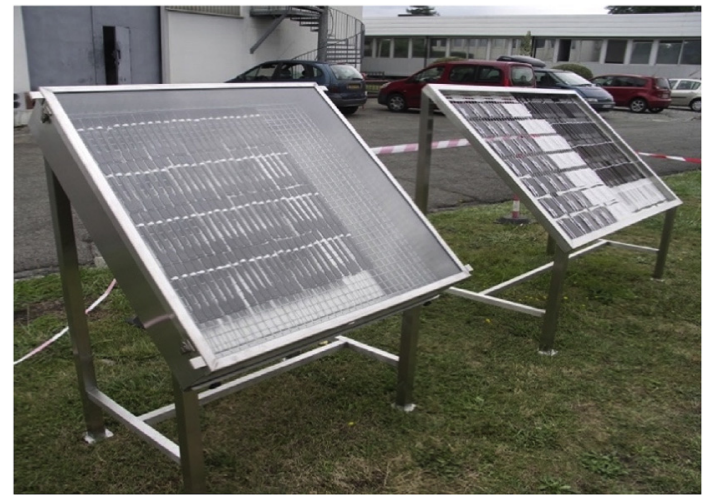

Fig. 1. Exterior and under glass exposure racks.

\subsection{Weathering}

Weathering tests were operated in Pau in the south west of France. Exterior and under windshield glass one-year expositions were chosen to represent exterior and interior applications of materials. Samples were exposed according to ISO 877-2011 standard [21,22]. The samples were fixed on galvanized racks at an angle of $45^{\circ}$ with the ground and directed toward the south direction. Laminated windshield glasses covered the materials for the automotive application (Fig. 1). Meteorological data from September 2015 to September 2016 were provided from Pau-Uzein station for outdoor parameters [23] whereas laboratory-sensors were used for under glasses monitoring. Data evolutions monitored all along the exposition are shown in Fig. 2. Changes in materials properties were measured (Table 1 ).

\subsection{Flexural tests}

Mechanical properties were measured by three-point bending test at $23 \pm 2{ }^{\circ} \mathrm{C}$ and $50 \pm 10 \% \mathrm{RH}$ on ISO $1 \mathrm{~A}$ dog-bone samples in accordance to the ISO 178:2010 standard. A Zwick TH 010 press apparatus and a $2.5 \mathrm{kN}$ load cell were used to characterize flexural properties. Values of elastic modulus $\mathrm{E}_{\mathrm{f}}$ and the stress at the conventional deflection $\sigma_{\mathrm{fc}}$ corresponding to the stress at a strain of $3.5 \%$ were calculated from stress-strain curves. The cross-head speeds were set at 2 and $100 \mathrm{~mm} \mathrm{~min}^{-1}$ for the modulus and flexural stress at the conventional deflection measurements respectively. Eight samples of each material were tested. Raw data has been reported in a previous paper [24].

\subsection{Differential Scanning Calorimetry (DSC)}

Calorimetric data were obtained through Differential Scanning Calorimetry (DSC) by means of a PYRIS Diamond calorimeter (Perkin Elmer, United States). The analysis was conducted under nitrogen atmosphere at a $20 \mathrm{~mL} \mathrm{~min}^{-1}$ constant flow. Surface fragments of almost $10 \mathrm{mg}$ were analysed. Samples were heated from 30 to $210^{\circ} \mathrm{C}$ with a heating ramp at $10^{\circ} \mathrm{C} \cdot \mathrm{min}^{-1}$. Two heating steps with an intermediate cooling step at $-10^{\circ} \mathrm{C} \cdot \mathrm{min}^{-1}$ were performed. Two replicate samples per material were analysed. The crystallinity rate was calculated according to the following equation from the melting enthalpy:

$\chi_{c}(\%)=\frac{\Delta H_{m}}{W \times \Delta H_{m 100}} \times 100$

with $\mathrm{W}$ the PP mass fraction, $\Delta \mathrm{Hm}\left(\mathrm{J}^{-\mathrm{g}^{-1}}\right)$ the melting enthalpy determined from the 2nd heating step and $\Delta \mathrm{Hm}_{100}$ the standard melting enthalpy of a $100 \%$ crystalline PP $\left(209 \mathrm{~J} \mathrm{~g}^{-1}\right)$ [8]. The 2nd heating cycle was chosen in order to overcome the crystallinity related to the thermal background of the polymer (processing). Otherwise, the second run provides information about the ability of degraded chains of the 

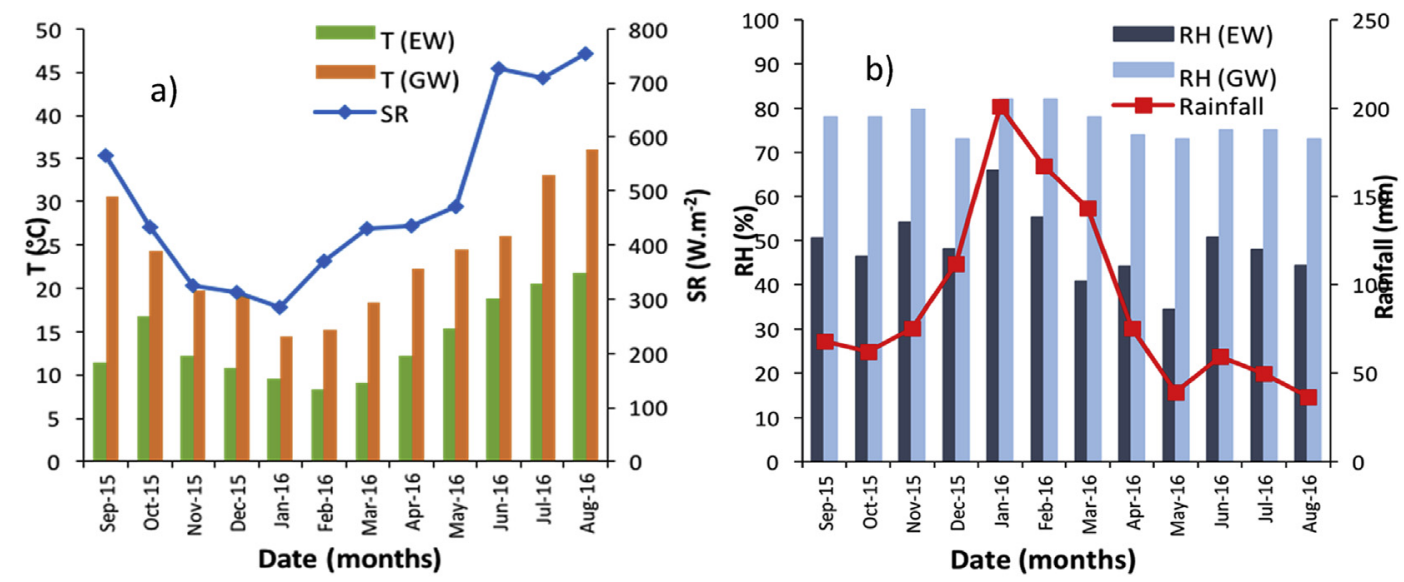

Fig. 2. Mean temperature (T) and mean solar radiation SR (a) and mean relative humidity (RH) and cumulative rainfall (b).

polymer to crystallize [10,25-28]. Moreover, same evolution tendencies of $\chi_{c}$ deduced from 1 st and 2 nd heating cycles were observed during the weathering. The primary data linked to crystallinity degrees are given elsewhere [24].

\subsection{Infrared spectroscopy}

A IFS66 spectrometer (Bruker, United States) operating in the Attenuated Total Reflectance (ATR) mode was used to follow vinyl and carbonyl bonds formation witnessing outdoor degradation. The device was equipped with a single reflection diamond crystal accessory. Exposed surfaces were analysed and the spectra were recorded as a result of the average of 32 scans in the 400 to $4000 \mathrm{~cm}^{-1}$ spectral range with a resolution of $1 \mathrm{~cm}^{-1}$. Infrared spectra were normalized according to the Min-Max normalization method with the $2925 \mathrm{~cm}^{-1}$ reference band assigned to the methylene groups. Spectra and absorbance values for specific peaks $\left(1711 \mathrm{~cm}^{-1}\right.$ for $\mathrm{C}=\mathrm{O}$ of carboxylic acids/ketones; $1740 \mathrm{~cm}^{-1}$ for $\mathrm{C}=\mathrm{O}$ of esters/aldehydes; $1780 \mathrm{~cm}^{-1}$ for $\mathrm{C}=\mathrm{O}$ of $\gamma$-lactones; $1650 \mathrm{~cm}^{-1}$ for $\mathrm{C}=\mathrm{C}$ of vinyls) were recorded and reported in a previous paper [24].

\subsection{Spectrocolorimetry}

The surface color analysis was performed by spectrocolorimetry on a Chroma Sensor CS3 (DataColor, United States). The CIE 1976 L*, $a^{*}$, $b^{*}$ uniform system was used to determine the lightness and the color. The $\mathrm{L}^{*}$ coordinate represents the lightness whereas $\mathrm{a}^{*}$ and $\mathrm{b}$ * represent the chromaticity. An increase of $L^{*}$ (from 0 to 100) demonstrates a material lightening. $\mathrm{a}^{*}$ and $\mathrm{b}^{*}$ are the chromaticity positions on axes from -300 to +300 axes from green $\left(-a^{*}\right)$ to red $\left(+a^{*}\right)$ and from blue $\left(-b^{*}\right)$ to yellow $\left(+b^{*}\right)$. Values, whose evolution can be observed in our recent paper [24], were obtained from the analysis of four areas of three samples.

\subsection{Spectrogoniometry}

A GON 360 goniometer (Instrument Service, Germany) coupled to a MAS 40 spectrometer equipped with a halogen lamp was used to collect the radiometric power. The source angle was fixed at $20^{\circ}$ according to ISO 2813 standard [29]. Detector angles varied from $5^{\circ}$ to $-60^{\circ}$ with an angular step smaller in the specular zone to detect the high variations of intensity in this zone. The distribution of the intensity of light reflected by a material according to the angle of detection allowed to characterize the gloss aspect [30]. $G_{1}$ corresponding to the haze gloss was determined from the ratio of the maximum intensity obtained for the angle of detection of $-20^{\circ} \mathrm{I}\left(\Theta=-20^{\circ}\right)$ to the intensity obtained for the angle of $-22^{\circ} \mathrm{I}\left(\Theta=-20+-2^{\circ}\right)$ both situated in the specular zone (Eq. (2)). The ratio of $\mathrm{I}\left(\Theta=-20^{\circ}\right)$ to the intensity collected for the angle of $-35^{\circ} \mathrm{I}\left(\Theta=-20+-15^{\circ}\right)$ of a diffusely reflected light far away from the specular zone was also calculated and corresponds to the contrast gloss (Eq. (2)). The higher the value of $\mathrm{G}_{1}$ and $\mathrm{G}_{2}$ are, the glossier and smoother the surface seems. The gloss was calculated for three replicates at four locations on each material and listed in our previous article [24].

$G 1=\frac{I\left(\theta=-20^{\circ}\right)}{I\left(\theta=-22^{\circ}\right)} \quad G 2=\frac{I\left(\theta=-20^{\circ}\right)}{I\left(\theta=-35^{\circ}\right)}$

\subsection{Rugosimetry}

A MICROMESURE STIL system equipped with a STIL CHR150 optical sensor was used to evaluate the roughness by altitude measurement of each surface point on the sample without contact with the sample according to the ISO 25178 international standard. More details are given in a previous paper [3]. A bidimensional scanning allows obtaining the image of the sample surface located at a precise distance from the STIL optical sensor. Acquisition software SurfaceMap allowed the control of the station and the post-treatment MountainsMap software was used to analyze the surface geometry and to calculate roughness parameters. The micrometric range of the optical pen was

Table 1

Designation of non-weathered and weathered PP, PP10 and PP30 materials.

\begin{tabular}{|c|c|c|c|}
\hline Ageing time (months) & Non-weathered materials & Exterior weathered materials & Under glass weathered materials \\
\hline 0 & PP-UW, PP10-UW, PP30-UW & - & - \\
\hline 1 & - & PP-EW1, PP10-EW1, PP30-EW1 & PP-GW1, PP10-GW1, PP30-GW1 \\
\hline 2 & - & PP-EW2, PP10-EW2, PP30-EW2 & PP-GW2, PP10-GW2, PP30-GW2 \\
\hline 3 & - & PP-EW3, PP10-EW3, PP30-EW3 & PP-GW3, PP10-GW3, PP30-GW3 \\
\hline 6 & - & PP-EW6, PP10-EW6, PP30-EW6 & PP-GW6, PP10-GW6, PP30-GW6 \\
\hline 9 & - & PP-EW9, PP10-EW9, PP30-EW9 & PP-GW9, PP10-GW9, PP30-GW9 \\
\hline 12 & - & PP-EW12,PP10-EW12, PP30EW12 & PP-GW12, PP10-GW12, PP30GW12 \\
\hline
\end{tabular}


$285 \mu \mathrm{m}$. It permits a tridimensional analysis and the analysed area $X * Y$ was $5 \mathrm{~mm} * 5 \mathrm{~mm}$ with an analysis step of $10 \mu \mathrm{m}$ in X and Y directions. The tridimensional roughness parameter Sa followed during the weathering corresponds to the arithmetic mean of the absolute of the height values (Eq. (3)):

$\mathrm{Sa}=\frac{1}{N M} \sum_{x=0}^{N-1} \sum_{y=0}^{M-1}|z(x, y)|$

with $\mathrm{M}$ the number of points along the $\mathrm{X}$ axis, $\mathrm{N}$ the number of points along the $\mathrm{Y}$ axis, and $\mathrm{z}_{\mathrm{x}, \mathrm{y}}$ the altitude in $\mu \mathrm{m}$. Mean values and standard deviations were obtained from the analysis of four areas of three samples. The evolution of roughness properties over the ageing was detailed elsewhere [24].

\subsection{Statistical analysis}

Principal Component Analysis (PCA) was carried out on Statistica 13 software (Dell, France). This multivariate statistical technique is used to make the cloud of the whole data (properties of all samples) easy to visualize it in a reduced dimension. For this purpose, a set of orthogonal principal components (axes) is built and variables (properties) are projected on a circle of correlations. The nature of relationships between variables depends on the angle formed between them. If they form an angle smaller than $90^{\circ}$ on the circle, a positive correlation exists between the variables [3,31]. The smaller the angle, the stronger the correlation. When two variables form an angle equals $90^{\circ}$, they are non-correlated. However, if the angle is higher than $90^{\circ}$, variables are anti-correlated, meaning if one variable increases, the other one decreases as well. To overcome the difference of units between all the properties (variables) for accurate interpretation, the standardization of the dataset by centering-reduction was used for the correlation circle representation:

$X_{i}^{\prime}=\frac{X_{i}-\bar{X}}{\sigma_{x}}$

where $\mathrm{X}_{\mathrm{i}}{ }^{\prime}$ is the centered-reduced variable, $\mathrm{X}_{\mathrm{i}}$ is the variable and $\overline{\mathrm{X}}$ and $\sigma_{\mathrm{x}}$ are the mean and standard deviation of the variable $\mathrm{X}$ respectively. The designations of variables (properties) are gathered in Table 2.

\section{Results and discussion}

\subsection{Treatment by fiber loading}

The correlation circle is the result of the projection of variables (properties) belonging to a multidimensional space on a two-dimension subspace. This circle allows verifying the correlations between properties by assessing the angle formed between their vectors. The correlation circles of PP, PP10 and PP30 dataset gathering non-weathered and weathered samples are illustrated in Fig. 3. The horizontal axis in

Table 2

Designation of parameters.

\begin{tabular}{ll}
\hline Designation & Parameter \\
\hline E & Modulus of elasticity (MPa) \\
s & Stress at the conventional deflection (MPa) \\
Xc & Crystallinity rate $\%$ ) \\
A1 & Absorbance $\mathrm{C}=\mathrm{O}$ at $1711 \mathrm{~cm}^{-1}$ (carboxylic acids/ketones) \\
A2 & Absorbance $\mathrm{C}=\mathrm{O}$ at $1740 \mathrm{~cm}^{-1}$ (esters/aldehydes) \\
A3 & Absorbance $\mathrm{C}=\mathrm{O}$ at $1780 \mathrm{~cm}^{-1}(\gamma$-lactones) \\
A4 & Absorbance $\mathrm{C}=\mathrm{C}$ at $1650 \mathrm{~cm}^{-1}$ (vinyls) \\
Sa & Roughness $(\mu \mathrm{m})$ \\
$\mathrm{G} 1$ & Haze gloss \\
$\mathrm{G} 2$ & Contrast gloss \\
$\mathrm{L}^{*}$ & Lightness (light-dark) \\
a* & Chromatic coordinate (red-green) \\
b* & Chromatic coordinate (yellow-blue) \\
\hline
\end{tabular}

the circle corresponding to the first principal component (PC1) accounts for the highest information rate $(66,71$ and $73 \%$ for PP, PP10 and PP30 respectively) which means that this axis brings the most of information on properties relationships existing in the primary multidimensional space. The statistical treatment by fiber loading induces an alignment of most of variables according to PC1, translating a high information rate of PC1. The maximum absorbance of infrared bands characteristic to oxidative degradation (A1, A2, A3) and chain scission (A4) and the surface aspect (Sa) are ones of the main parameters mostly contributing to PC1, in addition to crystallinity ratio Xc. Otherwise, the greater the fiber loading, the higher the global information share is retained by both PC1 and PC2. Thus, the higher vegetal fiber, the better the data is graphically summarised.

For both neat PP and biocomposites, an anti-correlation between mechanical properties and concentration of carboxylic acids, ketones and $\gamma$-lactones is observed. Therefore, the mechanical performance loss (elastic modulus $\mathrm{E}$ and stress at conventional deflection $\mathrm{s}$ decrease) could be quantitatively linked to their oxidative degradation (absorbance increase) since they are opposed. A small angle between lightness $\left(L^{*}\right)$ and $C=C$ vibration band (A4) vectors is raised on biocomposites correlation circles. The close link testified by the closeness between $\mathrm{L}^{*}$ and $\mathrm{A} 4$ could witness the contribution of lignin degradation by the increase of $\mathrm{C}=\mathrm{C}$ bonds in phenolic structures (A4 increase) responsible to further bleaching ( $\mathrm{L}^{*}$ increase) due to chromophores molecules generation $[4,10]$. Otherwise, the higher the fiber rate, the closer to PC2 b* chromatic coordinate is. Hence, $b *$ brings information distinct to the other variables.

Plans containing individuals (samples) are plotted in Fig. 4. The oxidation process and mechanical performance loss very close to PC1 qualify the evolution over the exposition (PC1) rather than the type of degradation (distinguished by PC2) since samples weathered from 1 to 12 months also evolve according to PC1. On the contrary, b* parameter mostly close to PC2 differentiated outdoor and under glass exposition since individuals belonging to PP30-GW group score high on PC2 while PP30-EW2, PP30-EW3 and PP30-EW6 score low. Indeed, yellowing was assigned to chromophore structures containing paraquinones whose formation seems to be favoured under the high temperatures recorded under windshield glass. Also, the two groups PP30-GW and PP30-EW are better organized and distinguished by PC2 than PP ones. This might be explained by the consequent influence of the type of weathering on the $b$ * chromatic parameter value linked to degradation of hemp fibers that preferentially undergo yellowing under glass promoted by high temperatures $[11,24]$. Also, for a same time of ageing, PP-EW and PPGW exhibit significantly different values according to PC1 with lower score for PP-EW, and hence high carbonyl and vinyl absorbance values, due to outdoor degradation factors that were more impactful. Therefore, the type of weathering had globally a bigger influence on PP properties changes during the exposure than on PP30.

\subsection{Treatment by time of weathering}

The relationships between properties after 1 and 12 months of weathering are depicted in Fig. 5 (values of properties recorded for nonweathered states were included as reference values in the two statistical analyses). The information rate of PC1 globally decreased from 1 to 12 months to the benefit of PC2 one. Thus, information of different nature is provided. At early stage of exposition (1 month), E, s, A1, A4, Sa on one hand, and $\mathrm{L}^{*}, \mathrm{G} 1, \mathrm{G} 2$ on the other hand, are respectively positively and negatively correlated with PC1 whereas A3 ( $\gamma$-lactones), A2 (esters and aldehydes) and a* color coordinate are described by PC2. However, they join PC1 after one year as well as mechanical parameters that came off PC1 and provide information through PC2. Individuals score plot will bring complementary insight to understand this evolution.

The average roughness gets anti-correlated with gloss parameters as the ageing time increases (12 months). Moreover, it is an acknowledged fact that the surface topography has a direct impact on brightness 

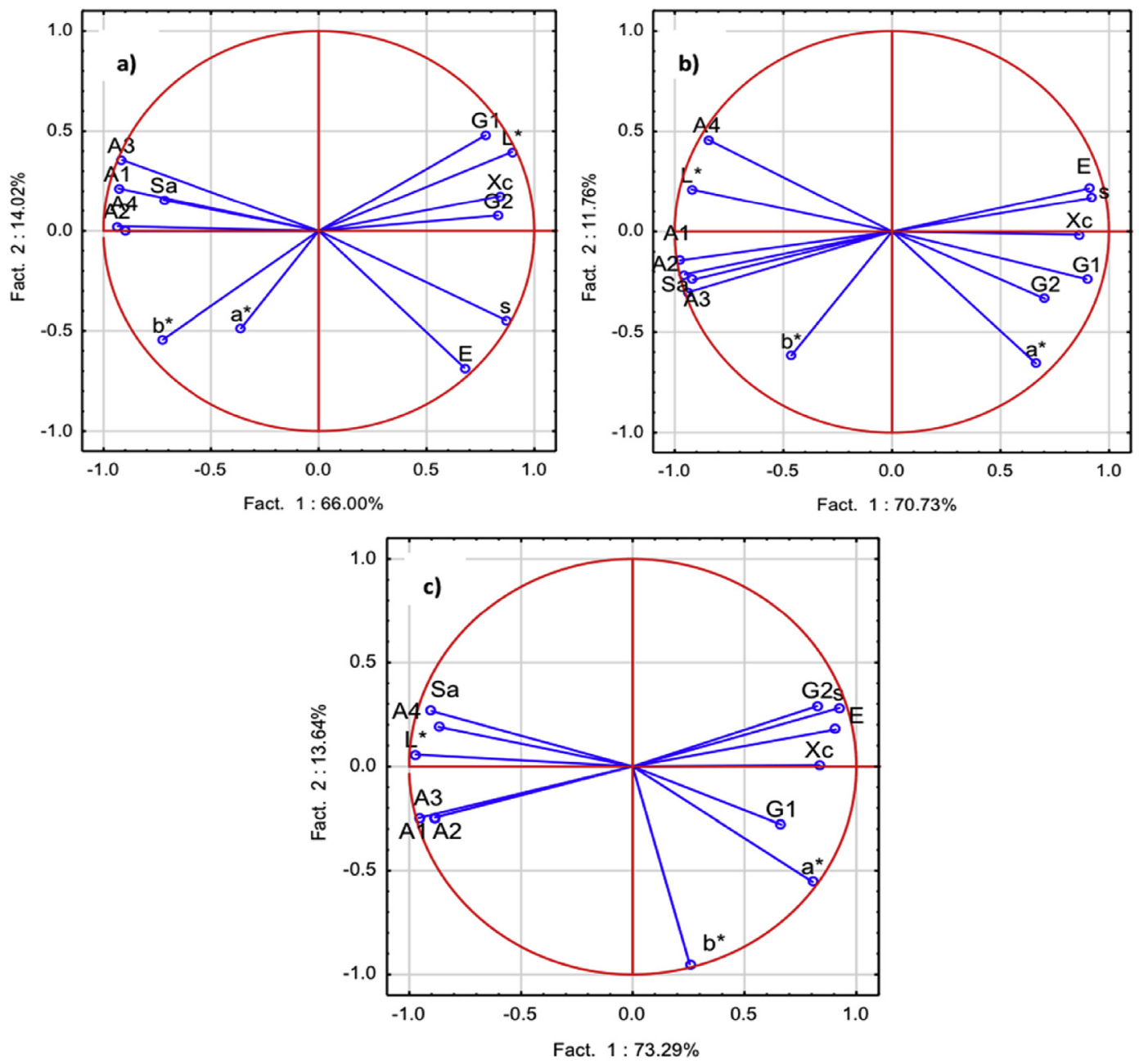

Fig. 3. Influence of the fiber loading: Correlation circles of PP (a), PP10 (b) and PP30 (c).

$[3,30]$, but Sa preferentially anti-correlates with G2 corresponding to contrast gloss rather than G1. G2 decrease could justify the sudden increase of roughness parameter at the same period whereas G1 remained almost constant. Similarly, crystallinity degree Xc and carbonyl functional groups absorbance are anti-correlated after 12 months whereas Xc headed in the same way as $\mathrm{A} 1$ at the beginning. Indeed, the decomposition of polymer chains firstly induced an increase of the degree of crystallinity due to chain scission in the amorphous phase promoting formation of short chains which rearrange into a crystalline phase $[9,16]$. Nevertheless, when chain scission continues further, the crystalline regions are affected and the crystallinity ratio decreases due to oxidative degradation whatever the material [32,33]. The unstable and reactive molecules formed through polymer decomposition oxidized and thus carbonyl absorption bands could increase to the detriment of the well-organized crystalline phase.

Scatterplots of individuals separated by weathering time are reported in Fig. 6. After 1 month, PP30 samples present lower values on PC1 than PP and PP10 ones i.e. high values in mechanical, $\mathrm{C}=\mathrm{O}$ and $\mathrm{C}=\mathrm{C}$ bonds and roughness properties since $\mathrm{E}, \mathrm{s}, \mathrm{A} 1$ and $\mathrm{A} 4$ are also positively correlated with PC1. Thus, these high values demonstrate high mechanical performance but also oxidation and surface aspect alteration due to presence of hemp fibers for PP30. The difference between the fiber loadings is better interpreted than weathering states at the beginning of exposition since all materials spread along PC1 whereas PC2, less informative, differences the states of weathering (UW, EW, GW) explained by a*, A2 and A3 that are close to PC2 (Fig. 5). This observation leads us to presume that reddening ( $a^{*}$ ) and presence of aldehydes (A2), esters (A2) and $\gamma$-lactones (A3) are particularly due to weathering rather than their naturally occurring presence in hemp fibers On the contrary, ketones and carboxylic acids (A1) close to PC1 differentiate PP, PP10 and PP30, which are separated according to PC1, and thus differentiate the hemp fiber rate.

However, the different states of weathering organize themselves according to PC1 after 12 months. So this reversal suggests that the variables linked to PC1 (absorbance, crystallinity and surface aspect including roughness and contrast gloss) further differentiate the states of the materials, either non-weathered or weathered, at a higher degree than at the beginning. So, long-term exposure obviously caused higher changes that are better characterized by PC1 whatever the material and the weathering type. As regards E and s, as they progress towards PC2 from 1 to 12 months, non-aged materials also progressively spread out along PC2 whereas EW and GW samples more and more align themselves on PC1. Therefore, mechanical performance defines the fiber loading mainly at non-weathered state. Indeed, difference of bulk properties (elastic modulus and conventional deflection stress values), between non-weathered PP, PP10 and PP30 is notable. On the contrary, their carbonyl and vinyl bonds peaks and crystallinity ratio, that are properties measured at the surface, are not so different. This can be explained by a major presence of polymer matrix at the material nonaged surface covering vegetal fibers and hence, leading to main analysis of PP properties. On the contrary, the exposition led to microstructure and absorbance differentiation between PP and biocomposites because of emergence of hemp fibers at the surface, to the detriment of distinction by bulk properties (mechanical performance) since their values 

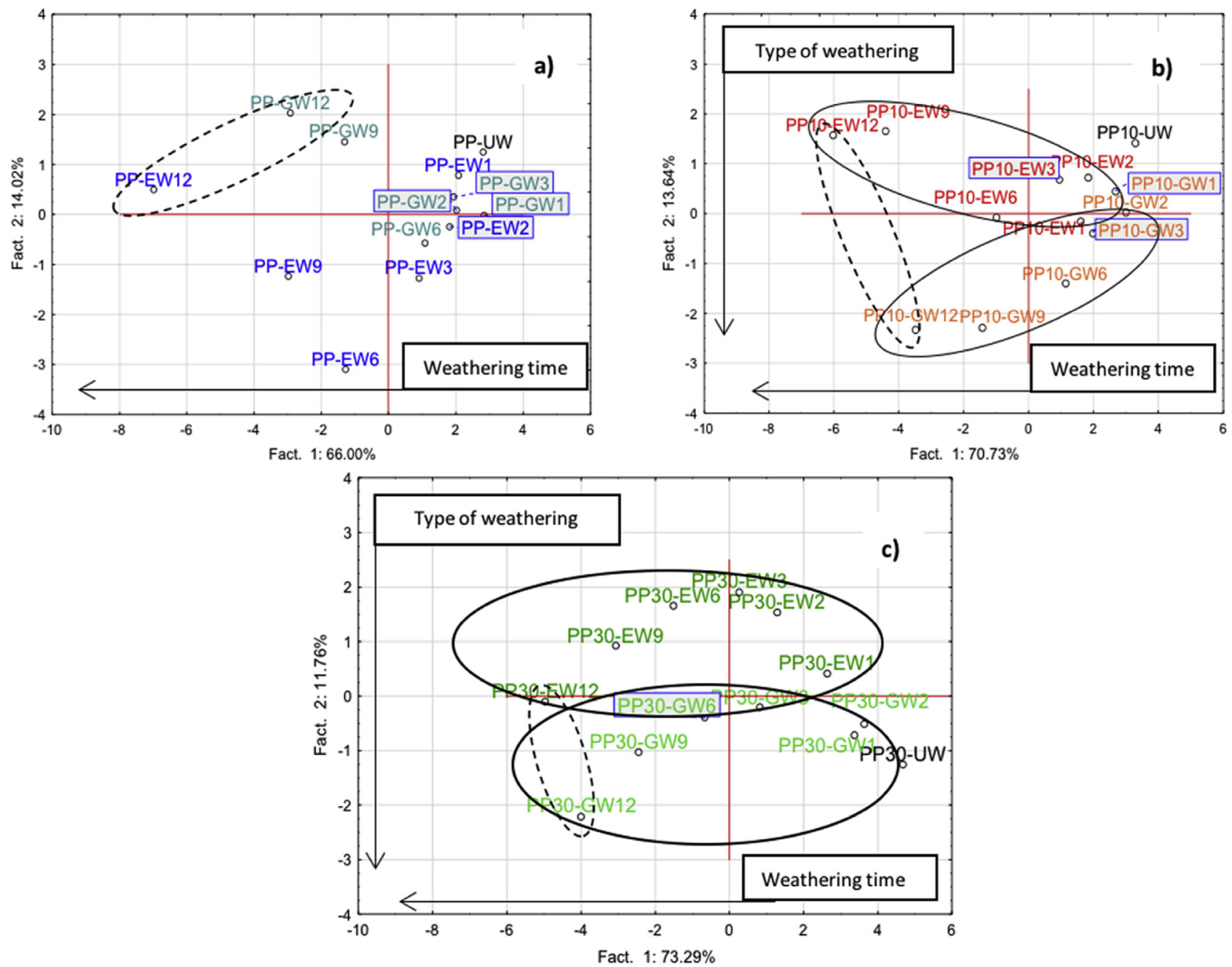

Fig. 4. Influence of the fiber loading: Individuals projection of PP (a), PP10 (b) and PP30 (c).

were not as different as non-weathered state values.

\section{Conclusion}

In this work, the relationships between properties of neat PP and natural fibers reinforced composites were determined. Statistical calculation by separation of materials by fiber loadings showed different individuals profiles. PP30-EW and PP30-GW clusters were well distinguished according to $\mathrm{b}^{*}$ coordinate meaning that the major parameter differentiating the biocomposites weathering conditions is the visual aspect (yellowing). Also, this representation allows prediction of mechanical performance loss thanks to carbonyl bands
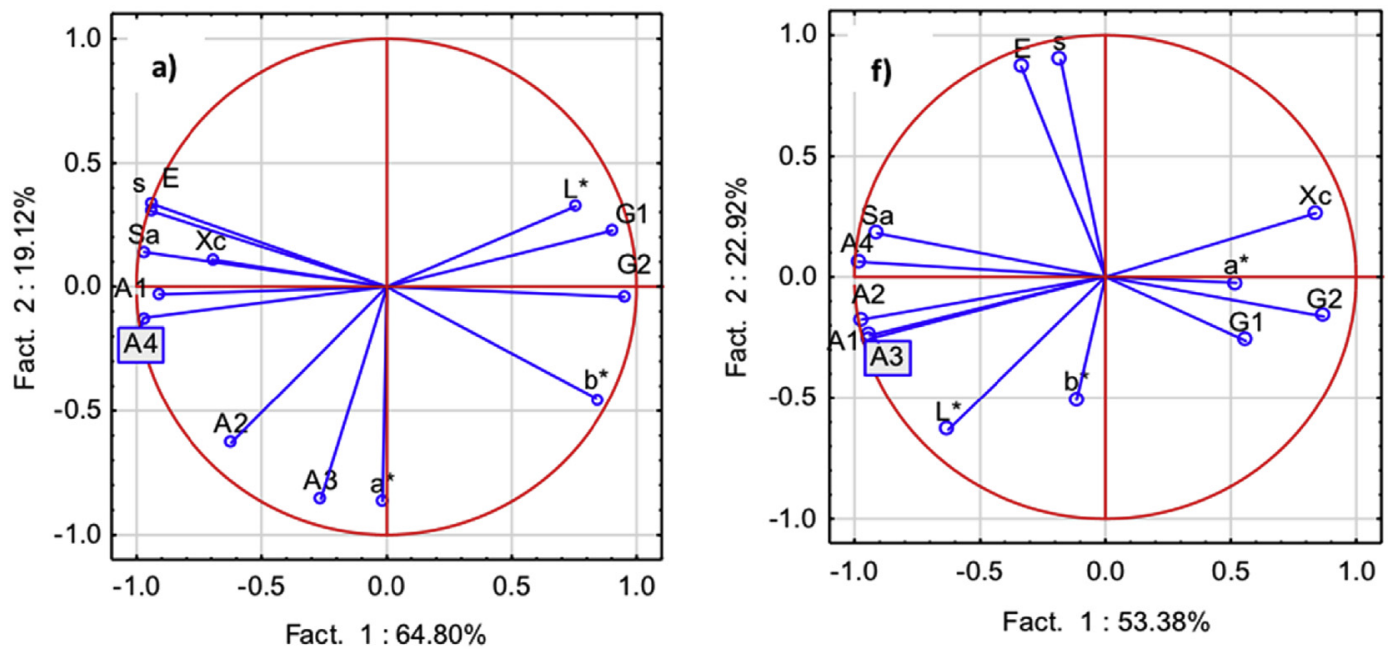

Fig. 5. Influence of the weathering duration: Correlation circles after 1 (a) and 12 months (f). 

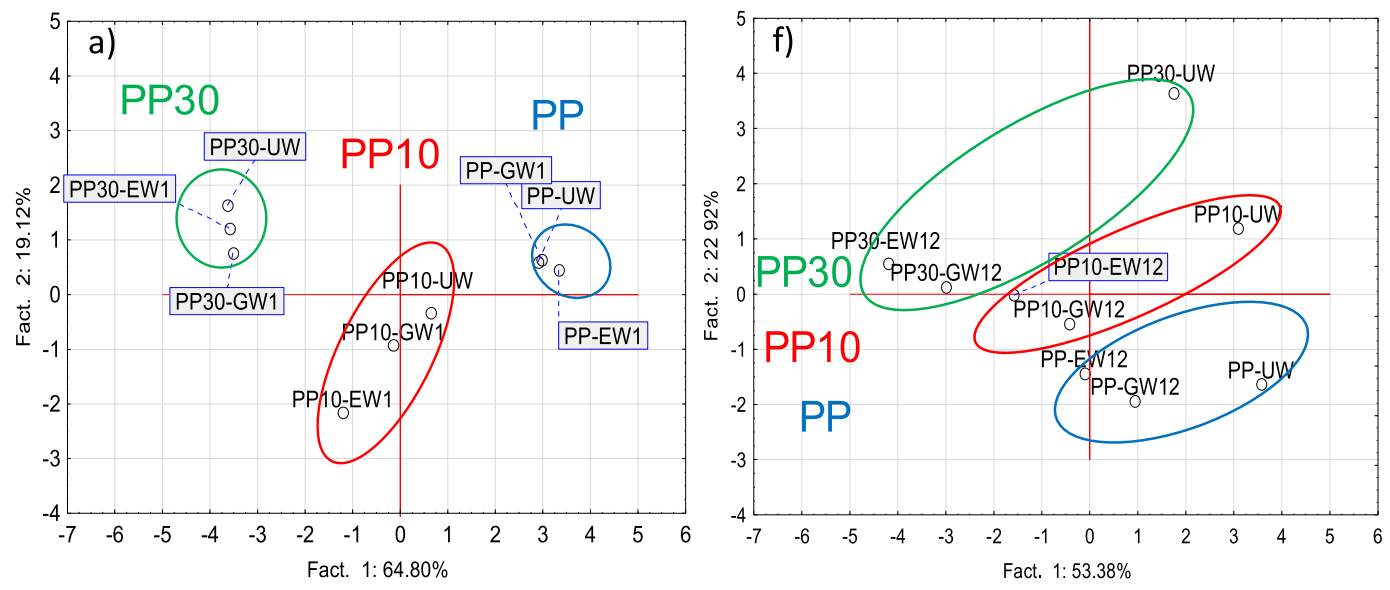

Fig. 6. Treatment by weathering duration: Projection of individuals after 1 (a) and 12 months (f).

monitoring. The intimate relationship found between $\mathrm{L}^{*}$ and $\mathrm{C}-\mathrm{C}$ double bond absorption band including $\mathrm{C}=\mathrm{C}$ of lignin structure for biocomposites, confirmed the contribution of lignin degradation reported in literature. Finally, an evolution of properties in the correlation circles was observed over the weathering. Firstly, the fiber loadings were discriminated by chemical bonds, surface aspect (roughness and contrast gloss) and crystallinity whereas state of weathering was characterized by these same variables after long-time exposition. Also, contrary to ketones and carboxylic acids, aldehydes and $\gamma$-lactones species were generated from weathering after short period rather than their naturally presence in vegetal fibers. This representation showed that bulk properties distinction was favoured at non-weathered state contrary to surface characteristics of materials that were differentiated after long-time exposition due to matrix decomposition. An anti-correlation between $\mathrm{C}=\mathrm{O}$ absorption bands and crystallinity ratio observed after long-time weathering was explained by the crystalline phase deterioration under oxidative degradation. After long-time exposition, degree of crystallinity and $\mathrm{C}=\mathrm{O}$ absorption bands also witnessed degradation rather than distinguish vegetal fibers rate.

\section{Acknowledgements}

This research did not receive any specific grant from funding agencies in the public, commercial, or not-for-profit sectors.

\section{References}

[1] M.M. Thwe, K. Liao, Durability of bamboo-glass fiber reinforced polymer matrix hybrid composites, Compos. Sci. Technol. 63 (2003) 375-387, https://doi.org/10. 1016/S0266-3538(02)00225-7.

[2] P.V. Joseph, M.S. Rabello, L.H.C. Mattoso, K. Joseph, S. Thomas, Environmental effects on the degradation behaviour of sisal fibre reinforced polypropylene composites, Compos. Sci. Technol. 62 (2002) 1357-1372, https://doi.org/10.1016/ S0266-3538(02)00080-5.

[3] C. Badji, L. Soccalingame, H. Garay, A. Bergeret, J.-C. Bénézet, Influence of weathering on visual and surface aspect of wood plastic composites: correlation approach with mechanical properties and microstructure, Polym. Degrad. Stabil. 137 (2017) 162-172, https://doi.org/10.1016/j.polymdegradstab.2017.01.010.

[4] L. Soccalingame, D. Perrin, J.-C. Bénézet, S. Mani, F. Coiffier, E. Richaud, A. Bergeret, Reprocessing of artificial UV-weathered wood flour reinforced polypropylene composites, Polym. Degrad. Stabil. 120 (2015) 313-327, https://doi.org/ 10.1016/j.polymdegradstab. 2015.07.013.

[5] L. Soccalingame, D. Perrin, J.-C. Bénézet, A. Bergeret, Reprocessing of UV-weath ered wood flour reinforced polypropylene composites: study of a natural outdoor exposure, Polym. Degrad. Stabil. 133 (2016) 389-398, https://doi.org/10.1016/j. polymdegradstab.2016.09.011.

[6] A. Le Duigou, P. Davies, C. Baley, Seawater ageing of flax/poly(lactic acid) biocomposites, Polym. Degrad. Stabil. 94 (2009) 1151-1162, https://doi.org/10. 1016/j.polymdegradstab.2009.03.025.

[7] A. Arbelaiz, B. Fernández, J.A. Ramos, A. Retegi, R. Llano-Ponte, I. Mondragon, Mechanical properties of short flax fibre bundle/polypropylene composites: influence of matrix/fibre modification, fibre content, water uptake and recycling, Compos. Sci. Technol. 65 (2005) 1582-1592, https://doi.org/10.1016/j. compscitech.2005.01.008.

[8] C. Rouillon, P.-O. Bussiere, E. Desnoux, S. Collin, C. Vial, S. Therias, J.-L. Gardette, Is Carbonyl Index a quantitative probe to monitor polypropylene photodegradation? Polym. Degrad. Stabil. 128 (2016) 200-208, https://doi.org/10.1016/j. polymdegradstab.2015.12.011.

[9] Y. Peng, R. Liu, J. Cao, Y. Chen, Effects of UV weathering on surface properties of polypropylene composites reinforced with wood flour, lignin, and cellulose, Appl. Surf. Sci. 317 (2014) 385-392, https://doi.org/10.1016/j.apsusc.2014.08.140.

[10] S. Butylina, M. Hyvärinen, T. Kärki, A study of surface changes of wood-polypropylene composites as the result of exterior weathering, Polym. Degrad. Stabil. 97 (2012) 337-345, https://doi.org/10.1016/j.polymdegradstab.2011.12.014.

[11] M. Muasher, M. Sain, The efficacy of photostabilizers on the color change of wood filled plastic composites, Polym. Degrad. Stabil. 91 (2006) 1156-1165, https://doi. org/10.1016/j.polymdegradstab.2005.06.024.

[12] M.R. Kantz, H.D. Newman, F.H. Stigale, The skin-core morphology and structureproperty relationships in injection-molded polypropylene, J. Appl. Polym. Sci. 16 (1972) 1249-1260, https://doi.org/10.1002/app.1972.070160516.

[13] N.M. Stark, L.M. Matuana, Surface chemistry and mechanical property changes of wood-flour/high-density-polyethylene composites after accelerated weathering, J. Appl. Polym. Sci. 94 (2004) 2263-2273, https://doi.org/10.1002/app.20996.

[14] D. Feng, D.F. Caulfield, A.R. Sanadi, Effect of compatibilizer on the structureproperty relationships of kenaf-fiber/polypropylene composites, Polym. Compos. 22 (2001) 506-517, https://doi.org/10.1002/pc.10555.

[15] W.Y. Chiang, W.D. Yang, B. Pukánszky, Polypropylene composites. II: structureproperty relationships in two-and three-component polypropylene composites, Polym. Eng. Sci. 32 (1992) 641-648.

[16] B. Fayolle, E. Richaud, X. Colin, J. Verdu, Review: Degradation-induced Embrittlement in Semi-crystalline Polymers Having Their Amorphous Phase in Rubbery State, (2008), pp. 6999-7012, https://doi.org/10.1007/s10853-0083005-3.

[17] P. Pagès, F.C.J. Saurina, X. Colom, FTIR and DSC study of HDPE structural changes and mechanical properties variation when exposed to weathering aging during Canadian winter, J. Appl. Polym. Sci. 60 (1996) 153-159.

[18] A. Torikai, A. Takeuchi, S. Nagaya, K. Fueki, Photodegradation of polyethylene effect of crosslinking on the oxygenated products and mechanical properties, Polym. Photochem. 7 (1986) 199-211.

[19] G. Akay, T. Tinçer, H.E. Ergöz, A study of degradation of low density polyethylene under natural weathering conditions, Eur. Polym. J. 16 (1980) 601-605, https:// doi.org/10.1016/0014-3057(80)90095-6.

[20] J.S. Fabiyi, A.G. McDonald, M.P. Wolcott, P.R. Griffiths, Wood plastic composites weathering: visual appearance and chemical changes, Polym. Degrad. Stabil. 93 (2008) 1405-1414, https://doi.org/10.1016/j.polymdegradstab.2008.05.024.

[21] ISO 877-1: Plastics - Methods of Exposure to Solar Radiation - Part 1: General Guidance, (2011).

[22] ISO 877-2: Plastics - Methods of Exposure to Solar Radiation - Part 2: Direct Weathering and Exposure behind Window Glass, (2011).

[23] Pau-uzein Meteorological Station, Real-time Weather Reports, (2016) http://www. infoclimat.fr/observations-meteo/temps-reel/pau-uzein/07610.html , Accessed date: 16 June 2017

[24] C. Badji, J. Beigbeder, H. Garay, A. Bergeret, J.-C. Bénézet, V. Desauziers, Exterior and under glass natural weathering of hemp fibers reinforced polypropylene biocomposites: impact on mechanical, chemical, microstructural and visual aspect properties, Polym. Degrad. Stabil. 148 (2018), https://doi.org/10.1016/j. polymdegradstab.2017.12.015.

[25] L. Sisti, G. Totaro, M. Vannini, P. Fabbri, S. Kalia, A. Zatta, A. Celli, Evaluation of the retting process as a pre-treatment of vegetable fibers for the preparation of highperformance polymer biocomposites, Ind. Crop. Prod. 81 (2016) 56-65, https://doi. org/10.1016/j.indcrop.2015.11.045.

[26] M. Groning, M. Hakkarainen, Headspace solid-phase microextraction with gas chromatography/mass spectrometry reveals a correlation between the degradation product pattern and changes in the mechanical properties during the 
thermooxidation of in-plant recycled polyamide 6,6, J. Appl. Polym. Sci. 86 (2002) 3396-3407, https://doi.org/10.1002/app.11345.

[27] K.B. Adhikary, S. Pang, M.P. Staiger, Accelerated ultraviolet weathering of recycled polypropylene-sawdust composites, J. Thermoplast. Compos. Mater. 22 (2009) 661-679, https://doi.org/10.1177/0892705709096550.

[28] C. Rouillon, P.O. Bussiere, E. Desnoux, S. Collin, C. Vial, S. Therias, J.L. Gardette, Is carbonyl index a quantitative probe to monitor polypropylene photodegradation? Polym. Degrad. Stabil. 128 (2016) 200-208, https://doi.org/10.1016/j. polymdegradstab.2015.12.011.

[29] ISO 2813: Coatings: Determination of Gloss Value at $20^{\circ}, 60^{\circ}$ and $85^{\circ},(2014)$, pp. $1-31$.
[30] R. Alexander-Katz, R.G. Barrera, Surface correlation effects on gloss, J. Polym. Sci. 36 (1997) 1321-1334.

[31] L.J. Williams, H. Abdi, Principal component analysis, Wiley Interdiscip. Rev. Comput. Stat. 2 (2010) 433-459, https://doi.org/10.1002/wics.101.

[32] C. Homkhiew, T. Ratanawilai, W. Thongruang, Effects of natural weathering on the properties of recycled polypropylene composites reinforced with rubberwood flour, Ind. Crop. Prod. 56 (2014) 52-59, https://doi.org/10.1016/j.indcrop.2014.02.034.

[33] N.M. Stark, L.M. Matuana, Influence of photostabilizers on wood flour-HDPE composites exposed to xenon-arc radiation with and without water spray, Polym. Degrad. Stabil. 91 (2006) 3048-3056, https://doi.org/10.1016/j.polymdegradstab. 2006.08.003. 